\title{
Genetic predisposition in the 2'-5'A pathway in the development of type 1 diabetes: potential contribution to dysregulation of innate antiviral immunity
}

\author{
Kristina Pedersen ${ }^{1}\left(\mathbb{D} \cdot\right.$ Martin Haupt-Jorgensen $^{1}$ (D) Lars Krogvold $^{2,3} \cdot$ Simranjeet Kaur $^{4}$ (D) Ivan C. Gerling ${ }^{5} \cdot$ \\ Flemming Pociot ${ }^{4,6}$ (D) $\cdot$ Knut Dahl-Jørgensen ${ }^{2,7}$ (D) $\cdot$ Karsten Buschard $^{1}$ (i)
}

Received: 9 October 2020 / Accepted: 4 March 2021 / Published online: 11 May 2021

(C) The Author(s) 2021

\begin{abstract}
Aims/hypothesis The incidence of type 1 diabetes is increasing more rapidly than can be explained by genetic drift. Viruses may play an important role in the disease, as they seem to activate the $2^{\prime}-5^{\prime}$-linked oligoadenylate $\left(2^{\prime}-5^{\prime} \mathrm{A}\right)$ pathway of the innate antiviral immune system. Our aim was to investigate this possibility.

Methods Innate antiviral immune pathways were searched for type 1 diabetes-associated polymorphisms using genome-wide association study data. SNPs within $\pm 250 \mathrm{~kb}$ flanking regions of the transcription start site of 64 genes were examined. These pathways were also investigated for type 1 diabetes-associated RNA expression profiles using laser-dissected islets from two to five tissue sections per donor from the Diabetes Virus Detection (DiViD) study and the network of Pancreatic Organ Donors (nPOD). Results We found 27 novel SNPs in genes nominally associated with type 1 diabetes. Three of those SNPs were located upstream of the $2^{\prime}-5^{\prime}$ A pathway, namely SNP rs4767000 $\left(p=1.03 \times 10^{-9}\right.$, OR 1.123$)$, rs1034687 $\left(p=2.16 \times 10^{-7}\right.$, OR 0.869$)$ and rs739744 ( $p=1.03 \times 10^{-9}$, OR 1.123). We also identified a large group of dysregulated islet genes in relation to type 1 diabetes, of which two were novel. The most aberrant genes were a group of IFN-stimulated genes. Of those, the following distinct pathways were targeted by the dysregulation (compared with the non-diabetic control group): OAS1 increased by $111 \%(p<1.00$ $\left.\times 10^{-4}, 95 \% \mathrm{CI}-0.43,-0.15\right) ; M X I$ increased by $142 \%\left(p<1.00 \times 10^{-4}, 95 \% \mathrm{CI}-0.52,-0.22\right)$; and $I S G 15$ increased by $197 \%(p$ $\left.=2.00 \times 10^{-4}, 95 \% \mathrm{CI}-0.68,-0.18\right)$.

Conclusions/interpretation We identified a genetic predisposition in the $2^{\prime}-5^{\prime} \mathrm{A}$ pathway that potentially contributes to dysregulation of the innate antiviral immune system in type 1 diabetes. This study describes a potential role for the $2^{\prime}-5^{\prime} \mathrm{A}$ pathway and other components of the innate antiviral immune system in beta cell autoimmunity.
\end{abstract}

Keywords $2^{\prime}-5^{\prime}$ A pathway $\cdot$ Interferon $\alpha \cdot 2^{\prime}-5^{\prime}$ Oligoadenylate synthetase $\cdot$ Ribonuclease $L \cdot R N a s e L \cdot$ Toll-like receptor $7 \cdot$ Type 1 diabetes $\cdot$ Type 1 interferon $\cdot$ Type 2 diabetes $\cdot$ Virus

Kristina Pedersen

kristina.pedersen@regionh.dk

The Bartholin Institute, Department of Pathology, Rigshospitalet, Copenhagen, Denmark

2 Division of Paediatric and Adolescent Medicine, Oslo University Hospital, Oslo, Norway

3 Faculty of Dentistry, University of Oslo, Oslo, Norway

4 Steno Diabetes Center Copenhagen, Gentofte, Denmark

5 Department of Medicine, University of Tennessee, Memphis, TN, USA

6 Faculty of Health and Medical Sciences, University of Copenhagen, Copenhagen, Denmark

7 Faculty of Medicine, University of Oslo, Oslo, Norway

Abbreviations
$\begin{array}{ll}\text { 2'-5'A } & \text { 2'-5'-Linked oligoadenylate } \\ \text { DiViD } & \text { Diabetes Virus Detection } \\ \text { dsRNA } & \text { Double-stranded RNA } \\ \text { eQTL } & \text { Expression quantitative trait locus } \\ \text { GWAS } & \text { Genome-wide association study } \\ \text { ISG } & \text { IFN-stimulated gene } \\ \text { MDA5 } & \text { Melanoma differentiation-associated 5 } \\ \text { nPOD } & \text { Network of Pancreatic Organ Donors } \\ \text { OAS } & \text { 2'-5' Oligoadenylate synthetase } \\ \text { PAMP } & \text { Pathogen-associated molecular pattern } \\ \text { Poly (I:C) } & \text { Polyinosinic:polycytidylic acid } \\ \text { PRR } & \text { Pathogen-recognition receptor } \\ \text { ssRNA } & \text { Single-stranded RNA }\end{array}$




\section{Research in context}

\section{What is already known about this subject?}

- Sporadic evidence suggests an association between the $2^{\prime}-5^{\prime}-$ linked oligoadenylate $\left(2^{\prime}-5^{\prime} A\right)$ pathway and type 1 diabetes

- Expression of 2'-5'A pathway genes in pancreatic beta cells is increased compared with alpha cells when mimicking a viral infection

\section{What is the key question?}

- Does polymorphism in genes from the 2'-5'A pathway of the innate antiviral immune system contribute to the pathogenesis of type 1 diabetes?

What are the new findings?

- Increased activation of the innate antiviral immune system is potentially deleterious for beta cells in individuals predisposed to type 1 diabetes

- The 2'-5'A pathway and IFN-stimulated gene products, such as myxovirus resistance (MX) proteins and IFNstimulated protein of $15 \mathrm{kDa}$ (ISG15), seem to be involved in the mechanism

How might this impact on clinical practice in the foreseeable future?

- Several potential biomarkers and targets for treatment, delay or prevention of type 1 diabetes were identified

\section{Introduction}

Type 1 diabetes is characterised by autoimmune $\mathrm{T}$ cell mediated destruction of pancreatic beta cells. Environmental factors may contribute to damage of beta cells and, particularly, viruses have been suspected to be implicated [1]. During a viral infection, the expression of type 1 IFN among the islet cells seems specific to beta cells [2]. Supporting the beta cell susceptibility hypothesis, it has been shown that treating alpha and beta TC3 cell lines with IFN- $\alpha$ and/or polyinosinic:polycytidylic acid [poly (I:C)], mimicking a viral infection, results in a six times higher $2^{\prime}-5^{\prime}$ oligoadenylate synthetase (OAS) response in beta cells compared with alpha cells [3]. Why beta cells are more vulnerable than alpha cells to viral infection may be due to nitric oxide toxicity, antigen mimicry and/or possibly dysregulation of IFN-stimulated genes (ISGs) such as those in the 2'-5'-linked oligoadenylate $\left(2^{\prime}-5^{\prime} \mathrm{A}\right)$ pathway. The cellular tolerance to infection is known to be regulated by the innate antiviral immune response and varies among tissues and cell types [4]. This is especially problematic for beta cells due to their high metabolic activity resulting in vulnerability (e.g. during a viral infection).

In individuals with type 1 diabetes, the expression of IFN- $\alpha$ is increased in the islets of Langerhans and peripheral blood. Inflammation mediated by IFN signalling can potentially drive programmed cell death in beta cells and initiate autoreactivity against beta cell antigens [5]. Type 1 IFNs display differential tissue expression and binding affinity to their receptor complexes, which give rise to various outcomes including inflammation and antiviral, antiproliferative and immunomodulatory activity. Thus, type 1 IFNs and ISGs may be the link between genetics, the immune system, and environmental factors that have been shown to contribute to autoimmunity in type 1 diabetes [6].

Stimulation of pathogen-recognition receptors (PRRs) by pathogen-associated molecular patterns (PAMPs) induce the production of proinflammatory cytokines and type I IFN, which leads to transcription of ISGs. Some of the welldescribed ISGs include ISG15, MX1,MX2, OAS1, OAS2, OAS3, OASL and RNASEL. OAS/RNase L, IFN-stimulated protein of $15 \mathrm{kDa}$ (ISG15), and Mx dynamin-like GTPase pathways show varying responsiveness to type 1 IFNs [7]. The 2'-5'A pathway, consisting of OAS proteins and the RNase L enzyme, is an RNA degradation pathway, which is induced by type 1 IFNs and activated by double-stranded RNA (dsRNA), an intermediate product of viral protein synthesis that is present in the cytosol of the cell. The activation of OAS by dsRNA results in polymerisation of ATP into 2'-5'A molecules. These 2'-5'A molecules activate latent RNase L, resulting in cleavage of single-stranded RNA (ssRNA) from viruses. However, RNase L can also inhibit protein synthesis of any other virus by cleaving host mRNA/ribosomal RNA, inhibiting translation. RNA cleaved by RNase $\mathrm{L}$ can then activate other cytoplasmic PRRs, resulting in further induction of type 1 IFN gene expression [8] and damage to the beta cell from within.

This study uses data from the genome-wide association study (GWAS) and islets transcriptomics from the Diabetes 
Virus Detection (DiViD) and the network of Pancreatic Organ Donors (nPOD) studies to investigate genetic variations and expression patterns in genes associated with innate antiviral immune pathways in relation to type 1 diabetes.

\section{Methods}

Tissue collection Pancreas biopsies $(n=5)$ were collected in the DiViD study as described previously [9]. Individuals with new-onset type 1 diabetes, 25-35 years of age, underwent a surgical minimal pancreatic tail resection by laparoscopy 3-9 weeks after diagnosis. The DiViD study was approved by the Norwegian Government's Regional Ethics Committee (reference 2009/1907). Tissue from donors who were autoantibodypositive ( $n=12)$, had longstanding type 1 diabetes $(n=20)$, had longstanding type 2 diabetes $(n=8)$, or who were non-diabetic (control group; $n=18$ ) was used for RNA analysis and was acquired from nPOD with approval from the University of Tennessee Health Science Center local Institutional Review Board (reference 10-00848-XM).

RNA analysis RNA analysis was conducted on snap-frozen tissue obtained from the DiViD [9] and nPOD [10] tissue collections. Optimal cutting temperature embedded tissue slides were subjected to laser capture of islets conducted as previously described [11]. In brief, all islets in two to five tissue sections from each donor were captured, pooled, and RNA extracted using the Arcturus PicoPure RNA Isolation Kit (Applied Biosystems, Grand Island, NY, USA). Quality and quantity of RNA was determined on a Bioanalyzer 2100 instrument (Agilent Technologies, Santa Clara, CA, USA); RNA integrity numbers are shown in electronic supplementary material (ESM) Table 1. Samples with sufficient quantity and quality of RNA were then subjected to gene expression analysis using Affymetrix expression arrays (GeneChip Human Gene 2.0 ST; Thermo Fisher) and global scaling as normalising method as previously described [12].

GWAS analysis GWAS analysis included 64 genes that were researched for genetic associations with type 1 diabetes. Immunochip SNPs for type 1 diabetes were retrieved from Onengut-Gumuscu et al [13]. A cut-off $p$ value $<0.01$ was used to retrieve nominally significant SNPs. SNPs within $\pm 250 \mathrm{~kb}$ flanking regions of the transcription start site of the examined genes were identified. We used Encyclopedia of DNA Elements (ENCODE) regulatory features from the University of California Santa Cruz genome browser [14] (http://genome.ucsc.edu/) and RegulomeDB [15] to identify potential regulatory SNPs that were likely to affect the expression of the associated genes. We also integrated data from multiple expression quantitative trait locus (eQTL) studies [16] to identify SNPs associated with changes in expression (cis-eQTL) of the associated gene. The $c i s-\mathrm{eQTL}$ effects were calculated using linear regression models in the selected tissues. Validated eQTLs from Westra et al [17] and GTEx2015_v6. GTEx2015_v6 eQTLs were computed using $\mathrm{a} \pm 1 \mathrm{Mb}$ cis window around the transcription start site. Significance was determined using a $Q$ value threshold. At least 70 samples per tissue are necessary to achieve the statistical power needed for this type of analysis. Predicted eQTL was calculated for pancreas and whole blood. Genotypetissue expression predictions calculation were performed in tissues with at least ten samples. No $Q$ value filtering was performed.

Statistical analysis Statistical analysis for RNA expression was performed using GraphPad Prism 8.0.2 (GraphPad, La Jolla, Ca, USA) and data are shown as mean \pm SEM. Outliers were detected in each group using the ROUT method and a total of 21 datapoints across all genes and groups were identified and removed. All groups were tested for normal distribution by the D'Agostino-Pearson and Anderson Darling test. For comparison between groups, one-way ANOVA was used with Dunnett's multiple comparison test and a 95\% CI. A $p$ value of $<0.05$ was considered significant (shown as ${ }^{*} p<0.05, * * p<0.01$ and ${ }^{* * *} p<0.001$ in figures).

\section{Results}

Selection of genes for analysis were based on their direct and/ or indirect association upstream and downstream of the $2^{\prime}-5^{\prime} \mathrm{A}$ pathway by examining the literature. We first conducted the GWAS study with 64 genes and, based on the resulting data, we selected 41 genes out of the original 64 for analysis of the RNA levels in islets from the nPOD and DiViD study. The individuals included in the GWAS study were all under the age of 17 years at diagnosis. In the nPOD study, the age at diagnosis was $3-26$ years. The DiViD study participants were aged 24-35 years at diagnosis.

SNPs in genes of the innate antiviral immune system show association to type 1 diabetes GWAS identified 22 genes with 167 (158 unique) associated SNPs having $p$ values $<0.01$ and ORs for the minor allele ranging from 0.5724 to 1.1841 (see ESM Table 2). Of these SNPs, 27 were nominally associated with type 1 diabetes. There were 15 genes that had at least one SNP with an eQTL $p$ value $<0.05$ in either whole blood (validated eQLT) or pancreas (predicted eQTL). By comparing those 15 genes to the genes analysed for RNA expression in islets, seven genes (denoted by superscript ' $\mathrm{a}$ ' in Tables 1 and 2) overlapped and were identified with significant type 1 diabetes SNPs with an eQTL signal.

Four SNPs with a strong type 1 diabetes association and an eQTL signal were seen in ADAR (encoding RNA-specific 
Table 1 Total number of SNPs related to the innate antiviral immune system and associated with type 1 diabetes

\begin{tabular}{|c|c|c|c|c|c|}
\hline Gene & $\begin{array}{l}\text { Total no. of T1D } \\
\text { SNPs }( \pm 250 \mathrm{~kb})\end{array}$ & No. of SNPs with eQTL signal & $\begin{array}{l}\text { SNP most strongly } \\
\text { associated with T1D }\end{array}$ & T1D SNP $p$ value & OR (minor/major allele) \\
\hline$A D A R^{\mathrm{a}, \mathrm{b}}$ & 9 & 7 & rs 4845625 & $1.32 \times 10^{-3}$ & $1.06 / 0.94$ \\
\hline CASP3 & 2 & 1 & rs $17075783^{b}$ & $4.46 \times 10^{-3}$ & $0.91 / 1.10$ \\
\hline CYBA & 4 & 2 & rs $4782429^{\mathrm{b}}$ & $4.21 \times 10^{-3}$ & $0.92 / 1.09$ \\
\hline$E I F 2 A K 2$ & 4 & 4 & rs $2247010^{\mathrm{b}}$ & $3.73 \times 10^{-3}$ & $0.94 / 1.06$ \\
\hline EIF3H & 1 & 1 & rs $1446534^{\mathrm{b}}$ & $1.69 \times 10^{-4}$ & $0.92 / 1.08$ \\
\hline GSPT1 & 2 & 1 & rs $350234^{\mathrm{b}}$ & $1.64 \times 10^{-2}$ & $1.05 / 0.95$ \\
\hline$I F I H I^{\mathrm{a}}$ & 90 & 50 & rs2111485 & $3.81 \times 10^{-18}$ & $0.85 / 1.18$ \\
\hline$I F N G^{\mathrm{a}}$ & 4 & 3 & rs11614178 & $1.55 \times 10^{-3}$ & $0.96 / 1.05$ \\
\hline$I L 1 R 1$ & 8 & 6 & rs $4850992^{\mathrm{b}}$ & $5.58 \times 10^{-3}$ & $0.75 / 1.34$ \\
\hline$I R F 7^{\mathrm{a}}$ & 2 & 1 & rs $17758^{\mathrm{b}}$ & $1.01 \times 10^{-2}$ & $0.87 / 1.15$ \\
\hline$M X 2^{\mathrm{a}, \mathrm{b}}$ & 2 & 1 & rs $7278439^{b}$ & $1.24 \times 10^{-3}$ & $0.95 / 1.05$ \\
\hline NOD2 & 4 & 4 & rs $2302759^{\mathrm{b}}$ & $4.11 \times 10^{-3}$ & $0.94 / 1.07$ \\
\hline$O A S 1^{\mathrm{a}}$ & 4 & 3 & rs $4767000^{\mathrm{b}}$ & $1.03 \times 10^{-9}$ & $1.12 / 0.89$ \\
\hline$O A S 3^{\mathrm{a}}$ & 3 & 2 & $\mathrm{rs} 4767000^{\mathrm{b}}$ & $1.03 \times 10^{-9}$ & $1.12 / 0.89$ \\
\hline TNFRSF1A & 15 & 3 & rs $10849451^{b}$ & $1.59 \times 10^{-3}$ & $1.06 / 0.94$ \\
\hline
\end{tabular}

${ }^{\mathrm{a}}$ Genes that also showed dysregulation on RNA expression level

${ }^{\mathrm{b}}$ Newly discovered in association with type 1 diabetes

T1D, type 1 diabetes

adenosine deaminase), ILIRI (encoding IL-1 receptor type 1), IRF7 (encoding IFN regulator 7) and the OAS gene family (Table 1). In ADAR, SNP rs4845625 (eQTL $p=1.32 \times 10^{-3}$ ) had an OR of 1.06 for the minor allele and was located $135 \mathrm{~kb}$ downstream of the gene. In ILIRI, the novel SNP rs4850992 (eQTL $p=5.58 \times 10^{-3}$ ) had an OR of 0.75 for the minor allele and was located $85 \mathrm{~kb}$ upstream of the gene. In IRF7, the novel SNP rs17758 (eQTL $p=1.01 \times 10^{-2}$ ) had an OR of 0.87 for the minor allele and was located $30 \mathrm{~kb}$ upstream of the gene. SNP rs4767000 (eQTL $p=1.03 \times 10^{-9}$ ) was located upstream of OAS1 and OAS3 with an OR of 1.12 for the minor allele. In $O A S 2, \mathrm{SNP}$ rs4767000 $\left(p\right.$ value $=1.03 \times 10^{-9}$, Table 2) also showed a significant $p$ value with an OR of 1.12 for the minor allele but it did not have an eQTL signal. Three SNPs were located upstream of the OAS genes (Fig. 1). These SNPs were associated with and novel to type 1 diabetes as well as related to $O A S 1, O A S 2$ and $O A S 3$. In addition to the aforementioned rs4767000, the others were rs1034687 ( $p=$ $2.16 \times 10^{-7}$, OR 0.869$)$ and rs739744 $\left(p=1.03 \times 10^{-9}\right.$, OR 1.123).

As shown in Table 2, the gene encoding IFN induced with helicase domain 1 (IFIH1) had four SNPs with significant predicted eQTLs in the pancreas: rs77088072 $(p=9.94 \times$ $10^{-3}$, OR 0.79); rs3788964 ( $p=3.99 \times 10^{-9}$, OR 0.86); rs3747517 $\left(p=4.98 \times 10^{-11}\right.$, OR 0.87); and rs13422767 ( $p$ $=5.33 \times 10^{-8}$, OR 0.87). The SNP rs3788964 was located $35 \mathrm{~kb}$ upstream of the transcription start site in IFIH1, rs 13422767 was located $24 \mathrm{~kb}$ downstream, and rs77088072 (a novel SNP in relation to type 1 diabetes) and rs3747517 were located inside the IFIH1 gene. The SNP rs2111485 (Table 1) was located $14 \mathrm{~kb}$ downstream of IFIH1 and was the SNP with the strongest eQTL signal associated with type 1 diabetes out of 90 SNPs found in this gene.

For IL1R1, rs4850992 ( $p=5.58 \times 10^{-3}$, OR 0.75) was located $87 \mathrm{~kb}$ upstream of the gene (Table 1). The SNP rs7565504 $\left(p=6.70 \times 10^{-3}\right.$, OR 0.75) was located $155 \mathrm{~kb}$ upstream of $I L 1 R I$, and the last SNP of interest in this gene was rs6731416 $\left(p=6.70 \times 10^{-3}\right.$, OR 0.75) located $160 \mathrm{~kb}$ upstream from transcription start site (Table 2). All three SNPs were to the best of our knowledge novel in relation to type 1 diabetes.

Genes of the innate antiviral immune system show dysregulated RNA expression associated with type 1 diabetes The heatmap revealed a strong dysregulation of most of the genes in individuals with new-onset type 1 diabetes from the DiViD study (Fig. 2). We selected 41 out of the 64 innate antiviral immune system genes analysed in the GWAS study for expression analysis in DiViD and nPOD islet tissue. Out of those 41 genes, two were novel in association with type 1 diabetes. Two genes showed lower RNA expression levels in autoantibody-positive individuals ( $p$ value $<0.05$ ). Thirteen genes showed either higher or lower expression levels in individuals with new-onset type 1 diabetes. Six genes showed higher expression levels in individuals with longstanding type 1 diabetes. Two genes showed higher expression levels and one gene was downregulated in 
Table 2 SNPs with an OR above 1.10 that were associated with type 1 diabetes

\begin{tabular}{|c|c|c|c|c|c|c|c|}
\hline \multirow[t]{2}{*}{ Gene } & \multicolumn{4}{|l|}{ SNP details } & \multirow{2}{*}{$\begin{array}{l}\text { Validated eQTL } \\
p \text { value in whole } \\
\text { blood }\end{array}$} & \multirow{2}{*}{$\begin{array}{l}\text { Predicted eQTL } \\
p \text { value in pancreas }\end{array}$} & \multirow{2}{*}{$\begin{array}{l}\text { Predicted eQTL } \\
p \text { value in } \\
\text { whole blood }\end{array}$} \\
\hline & SNP & $\begin{array}{l}p \text { value (without } \\
Q \text { value filtering) }\end{array}$ & $\begin{array}{l}\text { OR (minor } \\
\text { allele) }\end{array}$ & $\begin{array}{l}\text { OR (major } \\
\text { allele) }\end{array}$ & & & \\
\hline \multirow[t]{10}{*}{$I F I H 1^{\mathrm{a}}$} & rs $77088072^{b}$ & $9.94 \times 10^{-3}$ & 0.793 & 1.261 & & $1.40 \times 10^{-3}$ & $4.30 \times 10^{-3}$ \\
\hline & rs984971 & $2.40 \times 10^{-16}$ & 0.849 & 1.178 & & & $2.50 \times 10^{-2}$ \\
\hline & rs 2068330 & $3.64 \times 10^{-16}$ & 0.850 & 1.177 & & & $2.30 \times 10^{-2}$ \\
\hline & rs3788964 & $3.99 \times 10^{-9}$ & 0.858 & 1.165 & & $2.80 \times 10^{-2}$ & \\
\hline & rs $1549020^{\mathrm{b}}$ & $2.56 \times 10^{-12}$ & 0.863 & 1.158 & & & $4.80 \times 10^{-3}$ \\
\hline & rs 3747517 & $4.98 \times 10^{-11}$ & 0.871 & 1.148 & & $3.50 \times 10^{-2}$ & $2.20 \times 10^{-2}$ \\
\hline & rs13422767 & $5.33 \times 10^{-8}$ & 0.873 & 1.146 & & $1.50 \times 10^{-2}$ & \\
\hline & rs 13023380 & $2.56 \times 10^{-12}$ & 0.876 & 1.142 & & & $4.60 \times 10^{-2}$ \\
\hline & rs7608315 & $9.56 \times 10^{-11}$ & 0.884 & 1.131 & & & $2.50 \times 10^{-2}$ \\
\hline & rs $13022749^{b}$ & $1.60 \times 10^{-8}$ & 0.893 & 1.120 & & & $5.10 \times 10^{-3}$ \\
\hline$I F N A R I^{\mathrm{a}}$ & rs $2834136^{\mathrm{b}}$ & $1.36 \times 10^{-2}$ & 0.854 & 1.171 & & & \\
\hline$I F N G^{\mathrm{a}}$ & rs $7132610^{\mathrm{b}}$ & $3.18 \times 10^{-3}$ & 1.125 & 0.889 & & & \\
\hline \multirow[t]{4}{*}{$I L 1 R 1$} & rs79184888 b & $5.83 \times 10^{-3}$ & 0.753 & 1.328 & & & \\
\hline & rs $7565504^{\mathrm{b}}$ & $6.70 \times 10^{-3}$ & 0.754 & 1.326 & & & \\
\hline & rs6731416 & $6.70 \times 10^{-3}$ & 0.754 & 1.326 & & & \\
\hline & rs $140672656^{\mathrm{b}}$ & $6.33 \times 10^{-3}$ & 0.784 & 1.275 & & & \\
\hline \multirow[t]{2}{*}{$I R F 7^{\mathrm{a}}$} & rs118067545 & $8.48 \times 10^{-3}$ & 0.836 & 1.196 & & & \\
\hline & rs3993797 & $1.64 \times 10^{-2}$ & 0.887 & 1.128 & & & \\
\hline \multirow[t]{3}{*}{$O A S 1^{\mathrm{a}}$} & rs $1034687^{b}$ & $2.16 \times 10^{-7}$ & 0.869 & 1.150 & $2.19 \times 10^{-11}$ & & \\
\hline & rs $1015249^{b}$ & $1.25 \times 10^{-7}$ & 0.895 & 1.117 & $2.7 \times 10^{-13}$ & & \\
\hline & rs $739744^{\mathrm{b}}$ & $1.03 \times 10^{-9}$ & 1.123 & 0.890 & $1.11 \times 10^{-21}$ & & \\
\hline \multirow[t]{3}{*}{$O A S 2^{\mathrm{a}}$} & rs $1034687^{b}$ & $2.16 \times 10^{-7}$ & 0.869 & 1.150 & & & \\
\hline & rs $4767000^{\mathrm{b}}$ & $1.03 \times 10^{-9}$ & 1.123 & 0.890 & & & \\
\hline & rs $739744^{\mathrm{b}}$ & $1.03 \times 10^{-9}$ & 1.123 & 0.890 & & & \\
\hline \multirow[t]{2}{*}{$O A S 3^{\mathrm{a}}$} & rs $1034687^{b}$ & $2.16 \times 10^{-7}$ & 0.869 & 1.150 & & $1.30 \times 10^{-2}$ & \\
\hline & rs $739744^{\mathrm{b}}$ & $1.03 \times 10^{-9}$ & 1.123 & 0.890 & $1.32 \times 10^{-4}$ & & \\
\hline \multirow[t]{2}{*}{$S P 1$} & rs $17125267^{\mathrm{b}}$ & $1.03 \times 10^{-2}$ & 0.838 & 1.194 & & & \\
\hline & rs 11170466 & $1.47 \times 10^{-5}$ & 1.184 & 0.845 & & & \\
\hline
\end{tabular}

The SNPs in this table were selected based on their eQTL $p$ value in the specific tissues and their OR being above 1.10 for either the minor or the major allele

${ }^{a}$ Genes that also showed dysregulation on RNA expression level

${ }^{\mathrm{b}}$ Newly discovered in association with type 1 diabetes

longstanding type 1 diabetes. In general, the most aberrant genes were a group of IFGs.

PAMP recognition and IFN induction are increased in newonset type 1 diabetes Expression of the nine genes involved in the initial innate antiviral immune response is shown in Fig. 3. The expression of the gene encoding toll-like receptor 7 (TLR7) was significantly increased by $70 \%$ in individuals with new-onset type 1 diabetes compared with the non-diabetic control group ( $p=9.60 \times 10^{-3}, 95 \%$ CI $-0.42,-0.05$, Fig. 3b). IFNA1 expression was increased by $75 \%(p=1.30 \times$ $10^{-3}, 95 \%$ CI $-0.44,-0.09$, Fig. 3e) and IFNA10 expression was increased by $136 \%\left(p<1.00 \times 10^{-4}, 95 \% \mathrm{CI}-0.50\right.$, -0.18 , Fig. $3 \mathrm{f}$ ) in individuals with new-onset type 1 diabetes. Expression of IFNB $\left(p=4.00 \times 10^{-2}, 95 \% \mathrm{CI}-0.30,-0.006\right.$, Fig. $3 \mathrm{~g})$ and $I F N G\left(p=2.30 \times 10^{-3}, 95 \% \mathrm{CI}-0.32,-0.06\right.$, Fig. $3 \mathrm{~h}$ ) was increased by $58 \%$ and $65 \%$, respectively, in newonset type 1 diabetes. Interestingly, in the same group, expression of the gene encoding IFN- $\alpha$ and $-\beta$ receptor subunit 1 (IFNARI) was decreased by $47 \%\left(p=1.80 \times 10^{-2}, 95 \% \mathrm{CI}\right.$ $-0.04,-0.05$, Fig. $3 \mathrm{~d}$ ).

In individuals with longstanding type 1 diabetes, gene expression level was increased by $47 \%$ for TLR4 $(p=2.90 \times$ $10^{-2}, 95 \% \mathrm{CI}-0.29,-0.01$, Fig. $\left.3 \mathrm{a}\right)$ and $36 \%$ for $\operatorname{IL} 6(p=1.30$ 
Fig. 1 Overview of the OAS family of genes on chromosome 12 and the location of SNPs rs 1034687 , rs4767000 and rs 739744

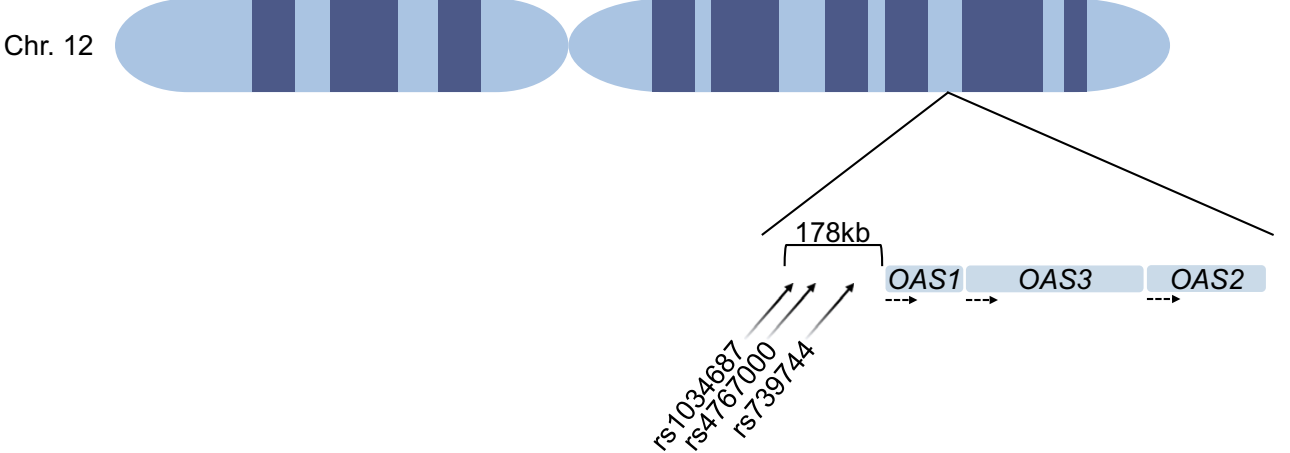

$\times 10^{-2}, 95 \% \mathrm{CI}-0.18,-0.02$, Fig. 3i). IRF7 expression was decreased by $17 \%$ in autoantibody-positive individuals $(p=$ $6.10 \times 10^{-3}, 95 \%$ CI $0.02,0.14$, Fig. $3 \mathrm{c}$ ); the expression of this gene was increased in longstanding type 1 diabetes by $14 \%$ ( $p$ $=4.00 \times 10^{-2}, 95 \% \mathrm{CI}-0.11,-0.002$, Fig. $\left.3 \mathrm{c}\right)$.

Multiple ISGs are highly elevated in new-onset type 1 diabetes In Fig. 4, the nine genes shown are upregulated or

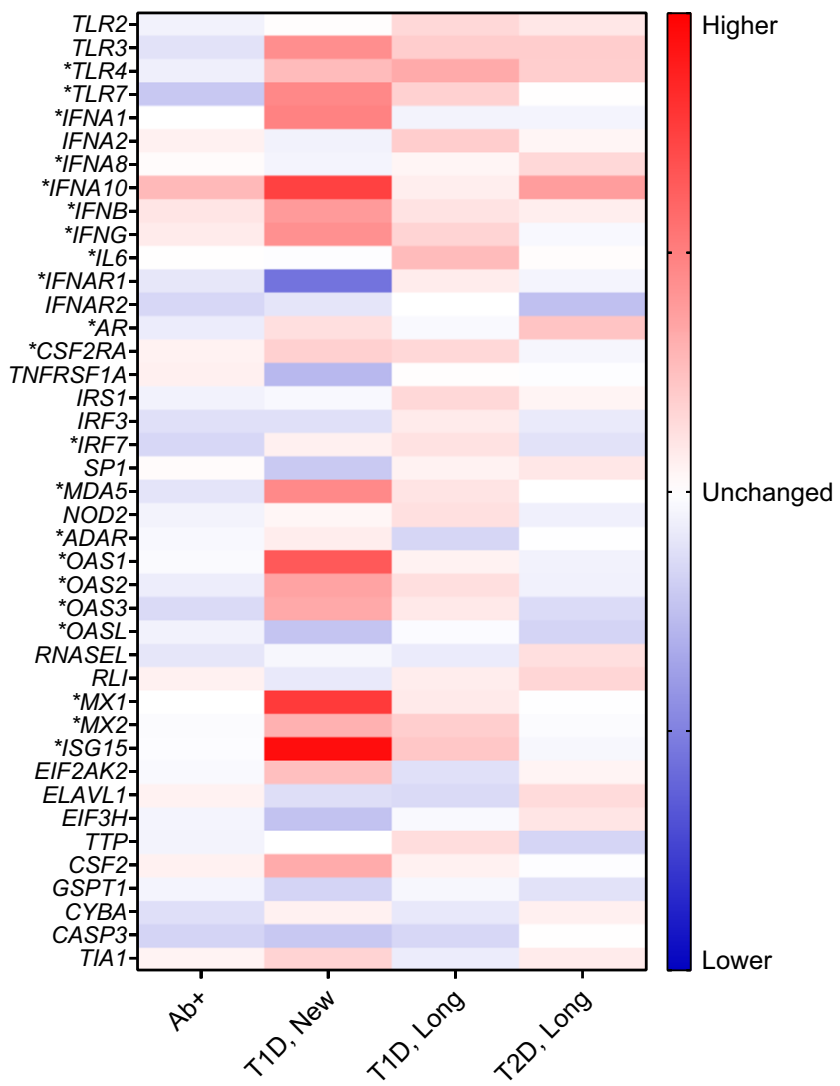

Fig. 2 Heatmap of RNA expression in the analysed genes. Genes were normalised to the non-diabetic control group by calculating the ratio of the means in each group. Blue indicates lower RNA expression compared with the control group and red indicates higher RNA expression level. A total of 21 genes showed significantly $(*)$ dysregulated RNA expression levels in either autoantibody-positive $(\mathrm{Ab}+)$, new-onset type 1 diabetes (T1D, New), longstanding type 1 diabetes (T1D, Long) or longstanding type 2 diabetes (T2D, Long) compared with controls downregulated by the genes (shown in Fig. 3) involved in the initial response of the innate antiviral immune pathway. In individuals with new-onset type 1 diabetes, the expression of OAS1 was increased by $111 \%\left(p<1.00 \times 10^{-4}, 95 \% \mathrm{CI}\right.$ $-0.43,-0.15$, Fig. $4 c)$, the expression of $M X 1$ was increased by $142 \%\left(p<1.00 \times 10^{-4}, 95 \% \mathrm{CI}-0.52,-0.22\right.$, Fig. $\left.4 \mathrm{~g}\right)$ and the expression of ISG15 was increased by $197 \%(p=2.00 \times$ $10^{-4}, 95 \%$ CI $-0.68,-0.18$, Fig. 4i) compared with nondiabetic control individuals. $O A S L$ expression was decreased by $23 \%\left(p=2.40 \times 10^{-2}, 95 \% \mathrm{CI}-0.06,-0.08\right)$ in individuals with new-onset type 1 diabetes (Fig. 4f). $M X 2$ expression was increased by $24 \%$ in individuals with longstanding type 1 diabetes $\left(p=3.80 \times 10^{-2}, 95 \% \mathrm{CI}-0.18,-0.004\right.$, Fig. $\left.4 \mathrm{~h}\right)$. Moreover, $A D A R$ expression was decreased by $17 \%$ in individuals with longstanding type 1 diabetes $\left(p=4.60 \times 10^{-2}\right.$, 95\% CI 0.001, 0.2, Fig. 4a).

\section{Discussion}

Our study is the first to investigate all major innate antiviral immune response pathways by combining analysis of GWAS data and analysis of RNA expression levels in islets from the DiViD and nPOD study populations. The GWAS study identified 168 type 1 diabetes-associated SNPs (159 unique SNPs), of which 27 were novel in relation to type 1 diabetes and are predicted to affect the expression of the associated genes. The islet RNA expression analysis identified two genes ( $A D A R$ and $M X 2$ ) that were novel in having a direct relation to type 1 diabetes, out of 19 dysregulated genes. The highest degree of dysregulation (13 genes) was seen in individuals with new-onset type 1 diabetes compared with non-diabetic individuals. In autoantibody-positive individuals two genes were dysregulated in those with longstanding type 1 diabetes, six genes were dysregulated and in those with type 2 diabetes, three genes were dysregulated at the mRNA level. We found multiple ISGs, such as the whole OAS family of genes, that were aberrant in individuals with type 1 diabetes and these genes had several SNPs associated with the disease. Another interesting result was found in genes upstream of the $2^{\prime}-5^{\prime} \mathrm{A}$ 
Fig. 3 Genes involved in PAMP recognition and IFN induction. The RNA expression levels of TLR4 (a), TLR7 (b), IRF7 (c), IFNARI (d), IFNA1 (e), IFNA10 (f), IFNB (g), IFNG (h) and IL6 (i) were transformed, and a mean was calculated. The ratio between the mean expression level in each group (autoantibody-positive $[\mathrm{Ab}+]$, new-onset type 1 diabetes [T1D, New], longstanding type 1 diabetes [T1D, Long], longstanding type 2 diabetes [T2D, Long]) and the nondiabetic control group was graphed. $* p<0.05, * * p<0.01$ and $* * * p<0.001$ vs control group
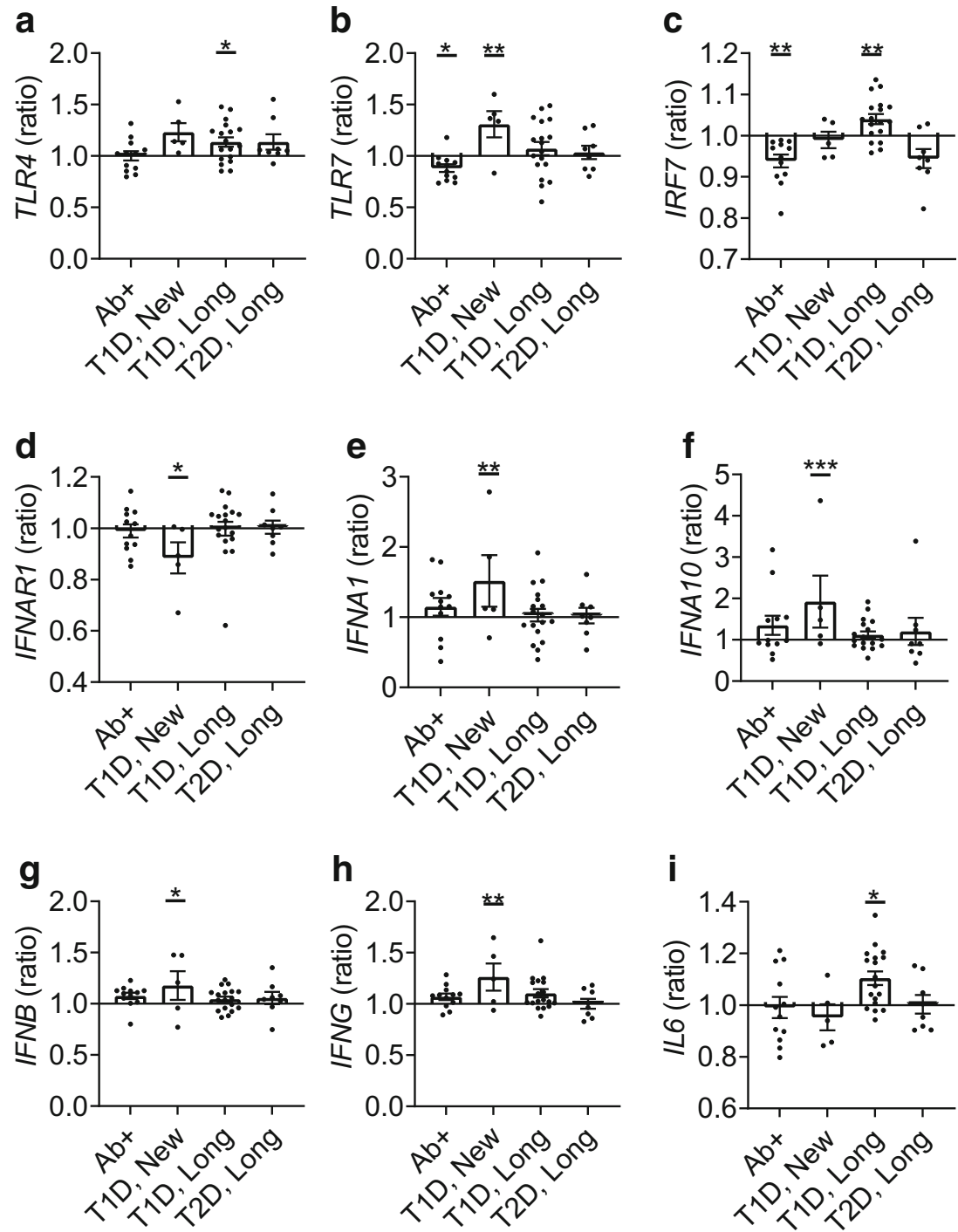

pathway, such as those encoding type 1 IFN and toll-like receptors.

The gene with the highest number of SNPs in our study was IFIH1, which is also referred to as MDA5 (encoding melanoma differentiation-associated 5 [MDA5] protein). This gene, a cytosol PRR that recognises dsRNA and prevents early replication of viruses, had 50 SNPs predicted to affect its expression. Several SNPs in IFIH1, which could be linked to risk of and protection against type 1 diabetes, have previously been identified and may modify the structure and function of IFIH1 [18].

The toll-like receptor genes and $I R F 7$ are important in the induction of type 1 IFN and upregulation of ISGs, especially the $2^{\prime}-5^{\prime}$ A pathway, and for further immune response through PRRs such as MDA5 [19]. Tight regulation of IRF7 expression and activity is imperative for appropriate type 1 IFN production [20]. A total of three SNPs were found in IRF7 and they could interfere with $I R F 7$ expression or its ability to bind a promoter region.

IFNAR1 was downregulated in individuals with new-onset type 1 diabetes and it had an SNP associated with type 1 diabetes. Moreover, several IFNA isoforms, as well as IFNB, were upregulated. IFN- $\alpha$ and IFN- $\beta$ share the IFN- $\alpha$ and $-\beta$ receptor subunit 1 as a common cell surface receptor. Interestingly, the receptor for the two cytokines, IFN- $\alpha$ and IFN- $\beta$, being downregulated but the cytokines themselves being upregulated could result in inflammation and destruction of beta cells in the islets of individuals with type 1 diabetes.

Beta cells are especially vulnerable to infection, potentially through dysregulation of the innate antiviral immune system leading to inflammation and destruction [2]. Dysregulation of IFN- $\alpha$ or the $2^{\prime}-5^{\prime}$ A pathway caused by either a genetic predisposition or environmental factors has been associated with type 1 diabetes in different ways. Moreover, studies 
Fig. 4 Cytokine genes and ISGs that were upregulated by IFN induction. The RNA expression levels of ADAR (a), IFIH1 (b), OAS1 (c), OAS2 (d), OAS3 (e), OASL (f), MX1 (g), MX2 (h) and ISGI5 (i) were transformed, and a mean was calculated. The ratio between the mean expression level in each group (autoantibody-positive [Ab+], new-onset type 1 diabetes [T1D, New], longstanding type 1 diabetes [T1D, Long], longstanding type 2 diabetes [T2D, Long]) and the nondiabetic control group was graphed. $* p<0.05$ and $* * * p<$ 0.001 vs control group
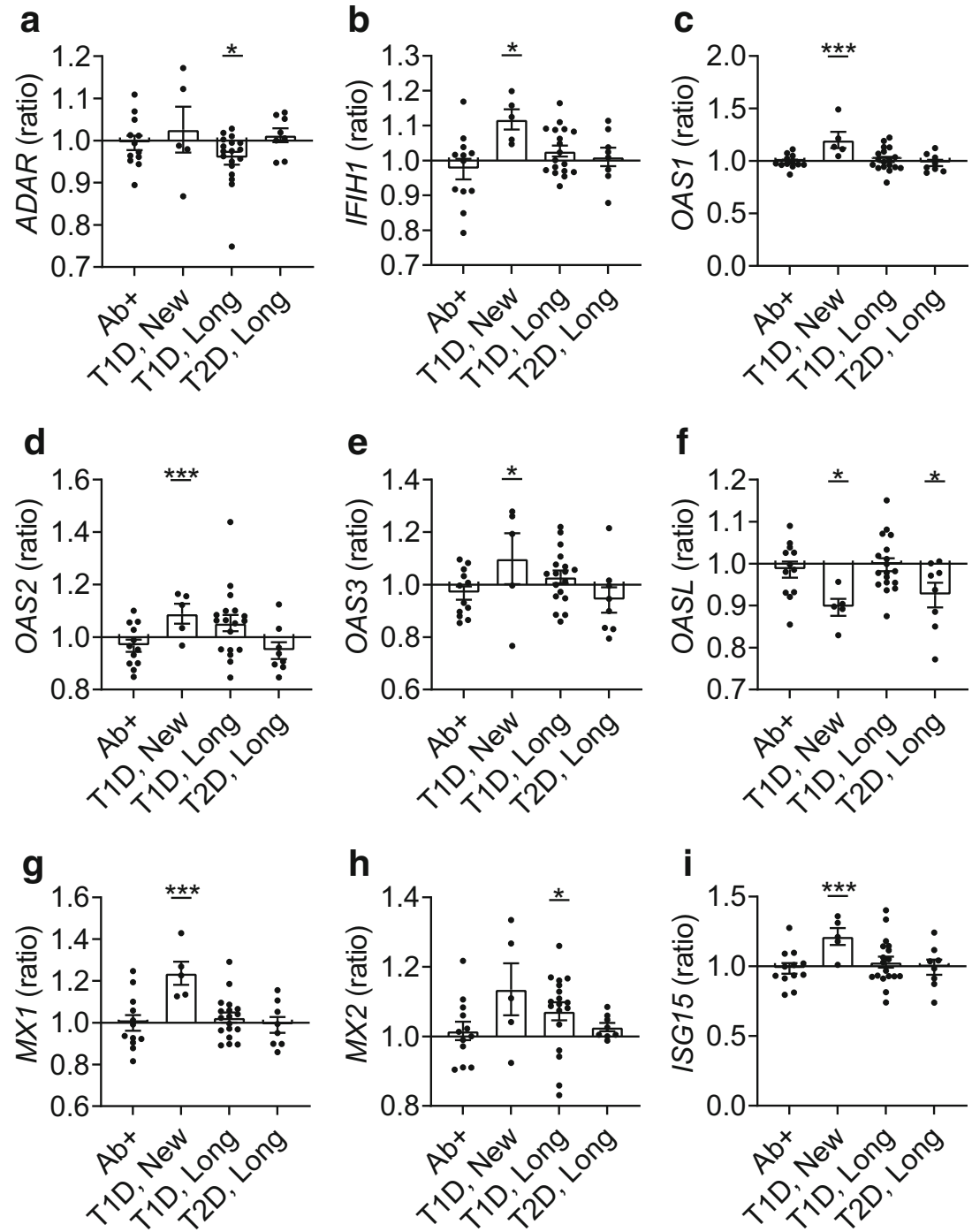

mimicking a viral response by poly (I:C) or type 1 IFN have shown that RNase L increases the expression of proinflammatory genes in the pancreas [21] and this might also contribute to the pathogenesis of type 1 diabetes.

The OAS genes were highly overexpressed in islets of individuals with new-onset type 1 diabetes and had several eQTL SNPs. In these individuals, OAS1, OAS2 and OAS3 were all upregulated whereas the $O A S L$ gene, which has an OAS-like domain but lacks the synthetase activity, was downregulated. We found three novel SNPs within the promoter region of $O A S 1, O A S 2$ and $O A S 3$ that could potentially affect the expression of the OAS family of genes. High levels of $O A S 1, O A S 2$ and $O A S 3$ indicate an antiviral response or a higher basal protein level in the cell. Whether OAS1, OAS2 and $O A S 3$ are able to properly activate RNase L [22] or other downstream proteins such as retinoic acid-inducible I or MDA5 is crucial for antiviral responses. Therefore, dysregulation of $O A S 1, O A S 2, O A S 3$ and $O A S L$ could indicate lack of the antiviral response and/or a higher degree of virus replication in the cell [23]. In addition, other studies have shown that the 2'-5'A pathway could potentially regulate expression of ISG15 [24], activate MDA5 and even influence IFN expression [8]. The OAS/RNase L activation has also been associated with programmed cell death even without the presence of a pathogen [25].

We found that $M X 1$ was upregulated in new-onset type 1 diabetes and that $M X 2$ was upregulated in longstanding type 1 diabetes as well as having two eQTL SNPs. Both $M X 1$ and $M X 2$, members of a gene family encoding dynamin-like large GTPases, suppress a wide but different variety of virus. Despite the similarities in sequence and structure, MX1 and MX2 have different mechanisms of action against viruses as well as which type of viruses they eliminate [26]. To the best of our knowledge, there is no previous evidence of a direct association between $M X 1$ and $M X 2$ and type 1 diabetes. Hence, this finding is novel and could be central for understanding virus-induced type 1 diabetes. 


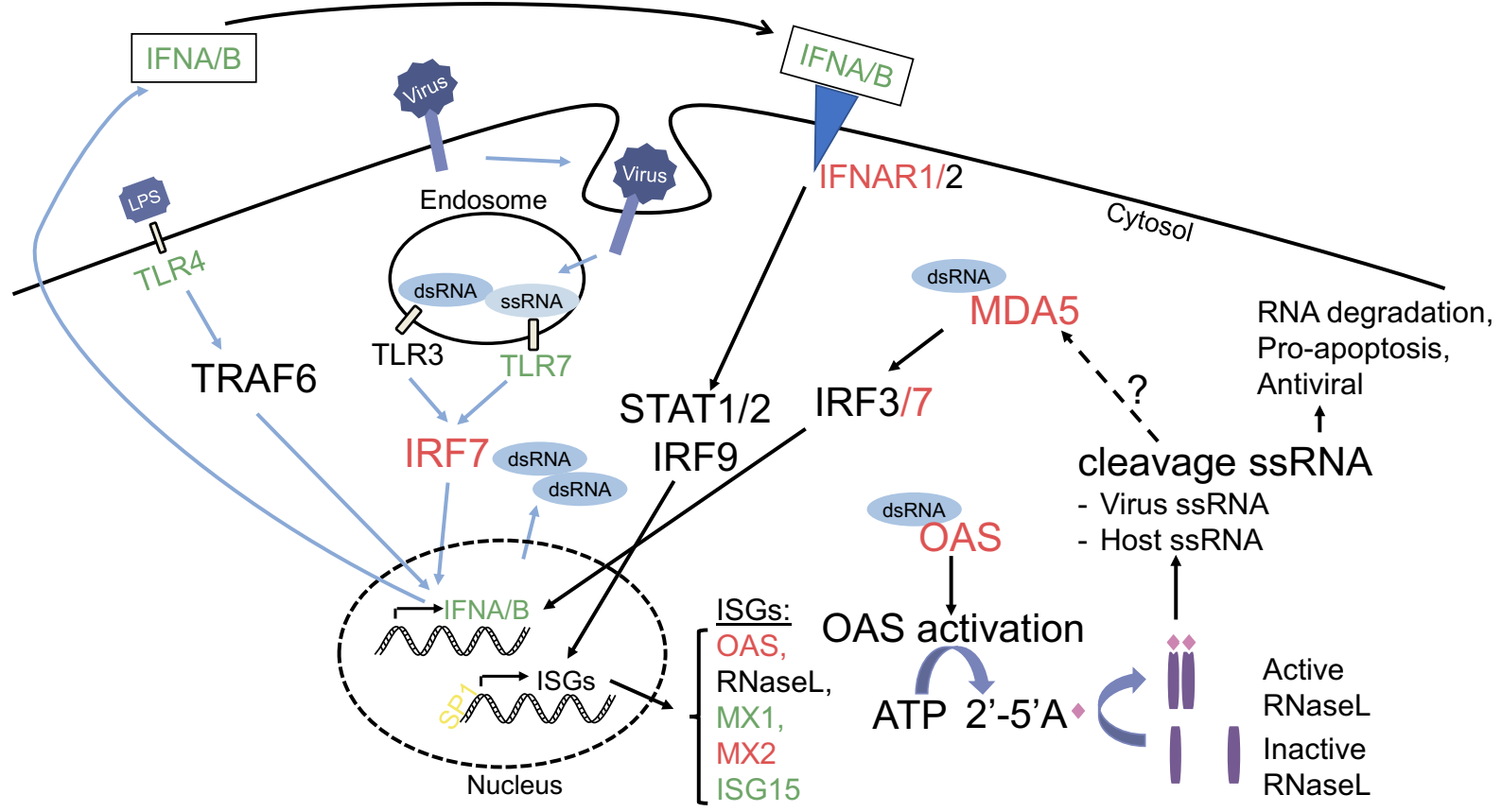

Fig. 5 The activation and the feedback loop of the innate antiviral immune system during a viral infection. The RNA dysregulated genes/ proteins where SNPs were also found in the GWAS study are highlighted in red. Genes/proteins that were only dysregulated at the RNA level are

The majority of ISGs were upregulated in individuals with new-onset type 1 diabetes; however, in longstanding type 1 diabetes $A D A R$ was downregulated and $M X 2$ was upregulated (both ISGs). The protein encoded by $A D A R$ has a dual role as it either modifies or regulates the innate antiviral immune response. It can prevent an unwanted MDA5 and type 1 IFN feedback loop by preventing MDA5 and OAS activation through A-to-I editing of dsRNA. However, if $A D A R$ is not regulated correctly, the Ato-I editing activity could either prevent or create an overactivation of an antiviral immune response.

Regarding type 2 diabetes, we only found three dysregulated genes at the mRNA level when compared with healthy control individuals, indicating that viral infection is not likely to contribute to this disease. $O A S L$ was downregulated and has shown effects on C-reactive protein, $\gamma$ glutamyltransferase and LDL-cholesterol, which are all related to cardiovascular events that are frequent in individuals with type 2 diabetes as well as inflammation [27].

Lundberg et al investigated the RNA expression of several innate antiviral immune system genes in laser-dissected islet tissue from the DiViD study, of which 20 samples were also analysed in our study. However, nPOD islet tissue and GWAS data were not included in this study, and a smaller control group $(n=5)$ was used [28]. As in our study, Lundberg et al [28] found the following genes to be significantly elevated: $I F I H 1 ; M X 1$; IL6; ISG15; and OAS1. This verifies an involvement of the innate antiviral immune response in new-onset type 1 diabetes.

A limitation of this study is the age difference between the individuals included in the GWAS study and the RNA highlighted in green. $S P 1$ is highlighted in yellow because we only found SNPs in this gene associated with type 1 diabetes. The figure illustrates the multitude of genes involved in the potential overactivation in response to an infection in type 1 diabetes. LPS, lipopolysaccharide

expression study. It is well known that in type 1 diabetes there are different endotypes, which can be defined according to age $[29,30]$. Thus, an endotype can be defined as those individuals diagnosed before the age of 7 years, those diagnosed after the age of 13 years, and those diagnosed between 7 and 12 years of age that can belong to either of the two endotypes. The pathogenesis of an endotype is defined by the type of infiltrating immune cells causing insulitis and by how much proinsulin and insulin are colocalised in beta cells [29]. In the current study, a direct association between the GWAS, the nPOD and DiViD cohorts should only be stated with caution, as the participants are from different endotypes. It is known that genetic variants in type 1 diabetes, typically located near genes and acting both in pancreatic beta cells and immune cells, are more prevalent in the endotypes diagnosed before the age of 7 years [30]. We were not able to correct for age, sex, BMI, HLA and/or autoantibody status due to small sample sizes; however, all this information can be found in ESM Table 1. This information can be combined with the information shown in ESM Figs 1 and 2, wherein each data point from the nPOD and DiViD analysis has an identifier correlating with information shown in ESM Table 1.

In conclusion, innate antiviral immune sensors capable of detecting and clearing ssRNA, were downregulated in autoantibody-positive individuals and upregulated in individuals with new-onset type 1 diabetes. These genes included TLR7, OAS, MX1, multiple type 1 IFN genes and IFIHI (Fig. 5). In conjunction, we found polymorphisms in $O A S$, $M X I$ and $I F I H I$ that indicate predisposition to type 1 diabetes. 
The DiViD study previously found footprints of virus in islets from individuals with type 1 diabetes [31]. Thus, we hypothesise that environmental factors (e.g. virus) in predisposed and/or autoantibody-positive individuals stimulate dysregulated $2^{\prime}-5^{\prime}$ pathway through toll-like receptor 7 and type 1 IFN in the innate immune system, causing inflammation in the islets and progression to diabetes. Identification and avoidance of diabetogenic viruses that can stimulate the toll-like receptor 7 pathway in early disease development may prevent or delay type 1 diabetes. It is our hope that further research on the role of toll-like receptors, the 2'-5'A pathway and other ISGs will lead to better prognostic markers and new therapeutic drugs.

Supplementary Information The online version contains peer-reviewed but unedited supplementary material available at https://doi.org/10.1007/ s00125-021-05469-5.

Acknowledgements The authors thank N. Lenchik from the Department of Medicine, University of Tennessee, Memphis, TN, USA for technical support in collecting gene expression data.

Data availability All data generated and analysed during this study are included in this published article and its ESM. Raw data are published online (https://www.dropbox.com/s/egshju5x6d4j0or/GWAS\%20study. xlsx?dl=0; https://www.dropbox.com/s/1r7lrxba1 fb0atk/nPOD\% 20and\%20DiViD\%20studies.csv?dl=0).

Funding The DiViD study was funded by the South-Eastern Norway Regional Health Authority, the Novo Nordisk Foundation, and through the PEVNET (Persistent Virus Infection in Diabetes Network) Study Group funded by the European Union's Seventh Framework Program (FP7/2007-2013) under grant agreement no. 261441 PEVNET. Additional grant support was from the National Institutes of Health (UC4 DK104155) and the JDRF (47-2013-520). nPOD, a collaborative type 1 diabetes research project, is sponsored by the JDRF (grant no. 252013-268, 25-2012-380 and 25-2007-874). Lastly, the study was supported by Bagger-Sørensen Foundation.

Authors' relationships and activities The authors declare that there are no relationships or activities that might bias, or be perceived to bias, their work.

Contribution statement $\mathrm{KP}, \mathrm{MHJ}$ and $\mathrm{KB}$ contributed to the conception and design of the study. KP, LK, SK, ICG, FP and KDJ acquired the data. KP analysed and interpreted data and drafted the manuscript. All authors revised the article critically and approved the final version. KP is the guarantor of the work and, as such, had full access to all the data in the study and takes responsibility for the integrity of the data and the accuracy of the data analysis.

Open Access This article is licensed under a Creative Commons Attribution 4.0 International License, which permits use, sharing, adaptation, distribution and reproduction in any medium or format, as long as you give appropriate credit to the original author(s) and the source, provide a link to the Creative Commons licence, and indicate if changes were made. The images or other third party material in this article are included in the article's Creative Commons licence, unless indicated otherwise in a credit line to the material. If material is not included in the article's Creative Commons licence and your intended use is not permitted by statutory regulation or exceeds the permitted use, you will need to obtain permission directly from the copyright holder. To view a copy of this licence, visit http://creativecommons.org/licenses/by/4.0/.

\section{References}

1. Roth R, Lynch K, Hyoty H et al (2019) The association between stressful life events and respiratory infections during the first 4 years of life: The Environmental Determinants of Diabetes in the Young study. Stress Health 35(3):289-303. https://doi.org/10.1002/smi.2861

2. Bonnevie-Nielsen V, Buschard K, Dyrberg T (1996) Differential responsiveness to interferon-alpha in beta-cells and non-beta cells. Diabetes 45(6):818-821. https://doi.org/10.2337/diab.45.6.818

3. Li M, Zheng DJ, Field LL, Bonnevie-Nielsen V (2009) Murine pancreatic beta TC3 cells show greater 2', 5'-oligoadenylate synthetase (2'5'AS) antiviral enzyme activity and apoptosis following IFN-alpha or poly(I:C) treatment than pancreatic alpha TC3 cells. Exp Diabetes Res 2009:631026. https://doi.org/10.1155/2009/ 631026

4. Marroqui L, Lopes M, dos Santos RS et al (2015) Differential cell autonomous responses determine the outcome of coxsackievirus infections in murine pancreatic alpha and beta cells. Elife 4: e06990. https://doi.org/10.7554/eLife.06990

5. Rodrigues KB, Dufort MJ, Llibre A et al (2020) Innate immune stimulation of whole blood reveals IFN-1 hyper-responsiveness in type 1 diabetes. Diabetologia 63(8):1576-1587. https://doi.org/10. 1007/s00125-020-05179-4

6. Bonnevie-Nielsen V, Larsen ML, Frifelt JJ, Michelsen B, Lernmark A (1989) Association of IDDM and attenuated response of 2',5'oligoadenylate synthetase to yellow fever vaccine. Diabetes $38(12)$ : 1636-1642. https://doi.org/10.2337/diab.38.12.1636

7. Sadler AJ, Williams BR (2008) Interferon-inducible antiviral effectors. Nat Rev Immunol 8(7):559-568. https://doi.org/10.1038/ nri2314

8. Malathi K, Dong B, Gale M Jr, Silverman RH (2007) Small selfRNA generated by RNase L amplifies antiviral innate immunity. Nature 448(7155):816-819. https://doi.org/10.1038/nature06042

9. Krogvold L, Edwin B, Buanes T et al (2014) Pancreatic biopsy by minimal tail resection in live adult patients at the onset of type 1 diabetes: experiences from the DiViD study. Diabetologia 57(4): 841-843. https://doi.org/10.1007/s00125-013-3155-y

10. Campbell-Thompson M, Wasserfall C, Kaddis J et al (2012) Network for Pancreatic Organ Donors with Diabetes (nPOD): developing a tissue biobank for type 1 diabetes. Diabetes Metab Res Rev 28(7):608-617. https://doi.org/10.1002/dmrr.2316

11. Richardson SJ, Rodriguez-Calvo T, Gerling IC et al (2016) Islet cell hyperexpression of HLA class I antigens: a defining feature in type 1 diabetes. Diabetologia 59(11):2448-2458. https://doi.org/10. 1007/s00125-016-4067-4

12. Wu J, Kakoola DN, Lenchik NI, Desiderio DM, Marshall DR, Gerling IC (2012) Molecular phenotyping of immune cells from young NOD mice reveals abnormal metabolic pathways in the early induction phase of autoimmune diabetes. PLoS One 7(10):e46941. https://doi.org/10.1371/journal.pone.0046941

13. Onengut-Gumuscu S, Chen WM, Burren O et al (2015) Fine mapping of type 1 diabetes susceptibility loci and evidence for colocalization of causal variants with lymphoid gene enhancers. Nat Genet 47(4):381-386. https://doi.org/10.1038/ng.3245

14. Rosenbloom KR, Sloan CA, Malladi VS et al (2013) ENCODE data in the UCSC Genome Browser: year 5 update. Nucleic Acids Res 41(Database issue):D56-D63. https://doi.org/10.1093/nar/ gks 1172 
15. Boyle AP, Hong EL, Hariharan M et al (2012) Annotation of functional variation in personal genomes using RegulomeDB. Genome Res 22(9):1790-1797. https://doi.org/10.1101/gr.137323.112

16. GTEx Consortium (2015) Human genomics. The Genotype-Tissue Expression (GTEx) pilot analysis: multitissue gene regulation in humans. Science 348(6235):648-660. https://doi.org/10.1126/ science. 1262110

17. Westra HJ, Peters MJ, Esko T et al (2013) Systematic identification of trans eQTLs as putative drivers of known disease associations. Nat Genet 45(10):1238-1243. https://doi.org/10.1038/ng.2756

18. Shigemoto T, Kageyama M, Hirai R, Zheng J, Yoneyama M, Fujita $\mathrm{T}$ (2009) Identification of loss of function mutations in human genes encoding RIG-I and MDA5: implications for resistance to type I diabetes. J Biol Chem 284(20):13348-13354. https://doi. org/10.1074/jbc.M809449200

19. Di Domizio J, Blum A, Gallagher-Gambarelli M, Molens JP, Chaperot L, Plumas J (2009) TLR7 stimulation in human plasmacytoid dendritic cells leads to the induction of early IFNinducible genes in the absence of type I IFN. Blood 114(9):1794 1802. https://doi.org/10.1182/blood-2009-04-216770

20. Wang Z, Zheng Y, Hou C et al (2013) DNA methylation impairs TLR9 induced Foxp3 expression by attenuating IRF-7 binding activity in fulminant type 1 diabetes. J Autoimmun 41:50-59. https://doi.org/10.1016/j.jaut.2013.01.009

21. Zeng C, Yi X, Zipris D et al (2014) RNase L contributes to experimentally induced type 1 diabetes onset in mice. J Endocrinol 223(3):277-287. https://doi.org/10.1530/JOE-14-0509

22. Li Y, Banerjee S, Wang Y et al (2016) Activation of RNase L is dependent on OAS3 expression during infection with diverse human viruses. Proc Natl Acad Sci U S A 113(8):2241-2246. https://doi.org/10.1073/pnas.1519657113

23. Zhu J, Zhang Y, Ghosh A et al (2014) Antiviral activity of human OASL protein is mediated by enhancing signaling of the RIG-I RNA sensor. Immunity 40(6):936-948. https://doi.org/10.1016/j. immuni.2014.05.007

24. Li XL, Blackford JA, Judge CS et al (2000) RNase-L-dependent destabilization of interferon-induced mRNAs. A role for the 2-5A system in attenuation of the interferon response. J Biol Chem 275(12):8880-8888. https://doi.org/10.1074/jbc.275.12.8880

25. Birdwell LD, Zalinger ZB, Li Y et al (2016) Activation of RNase L by murine coronavirus in myeloid cells is dependent on basal Oas gene expression and independent of virus-induced interferon. J Virol 90(6):3160-3172. https://doi.org/10.1128/JVI.03036-15

26. Fribourgh JL, Nguyen HC, Matreyek KA et al (2014) Structural insight into HIV-1 restriction by MxB. Cell Host Microbe 16(5): 627-638. https://doi.org/10.1016/j.chom.2014.09.021

27. Middelberg RP, Ferreira MA, Henders AK et al (2011) Genetic variants in LPL, OASL and TOMM40/APOE-C1-C2-C4 genes are associated with multiple cardiovascular-related traits. BMC Med Genet 12:123. https://doi.org/10.1186/1471-2350-12-123

28. Lundberg M, Krogvold L, Kuric E, Dahl-Jorgensen K, Skog O (2016) Expression of interferon-stimulated genes in insulitic pancreatic islets of patients recently diagnosed with type 1 diabetes. Diabetes 65(10):3104-3110. https://doi.org/10.2337/db16-0616

29. Leete P, Oram RA, McDonald TJ et al (2020) Studies of insulin and proinsulin in pancreas and serum support the existence of aetiopathological endotypes of type 1 diabetes associated with age at diagnosis. Diabetologia 63(6):1258-1267. https://doi.org/10. 1007/s00125-020-05115-6

30. Inshaw JRJ, Cutler AJ, Crouch DJM, Wicker LS, Todd JA (2020) Genetic variants predisposing most strongly to type 1 diabetes diagnosed under age 7 years lie near candidate genes that function in the immune system and in pancreatic beta-cells. Diabetes Care 43(1): 169-177. https://doi.org/10.2337/dc19-0803

31. Krogvold L, Edwin B, Buanes T et al (2015) Detection of a lowgrade enteroviral infection in the islets of langerhans of living patients newly diagnosed with type 1 diabetes. Diabetes 64(5): 1682-1687. https://doi.org/10.2337/db14-1370

Publisher's note Springer Nature remains neutral with regard to jurisdictional claims in published maps and institutional affiliations. 